2017-3

\title{
Globalworkit - Connecting Leading Information and Communications Technology (ICT) Sectors
}

Deirdre Lillis

Technological University Dublin, deirdre.lillis@tudublin.ie

Michael Collins

Technological University Dublin, michael.collins@tudublin.ie

Follow this and additional works at: https://arrow.tudublin.ie/scschcomcon

\section{Recommended Citation}

Collins, M. \& Lillis, D. (2017). Globalworkit - Connecting Leading Information and Communications Technology (ICT) Sectors. 11th annual International Technology, Education and Development Conference, INTED2017, Valencia (Spain). doi:10.21125/inted.2017.0546

This Conference Paper is brought to you for free and open access by the School of Computer Sciences at ARROW@TU Dublin. It has been accepted for inclusion in Conference papers by an authorized administrator of ARROW@TU Dublin. For more information, please contact arrow.admin@tudublin.ie, aisling.coyne@tudublin.ie,gerard.connolly@tudublin.ie. Funder: EACEA

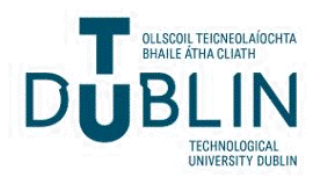




\title{
GLOBALWORKIT - CONNECTING LEADING INFORMATION AND COMMUNICATIONS TECHNOLOGY (ICT) SECTORS
}

\author{
Michael Collins, Deirdre Lillis \\ Dublin Institute of Technology (IRELAND)
}

\begin{abstract}
GlobalWorkIT prepares European and Korean students for employment in the international information and communications technology (ICT) industry by enhancing understanding of global issues in the ICT sector and of the languages and cultures of the participant countries. It connects three European and three Korean Higher Education Institutions located in world-leading ICT sectors (Korea, Ireland, Germany and Finland) and leverages their relationships with ICT companies that are innovationfocused and internationally-oriented. In this paper, we present GlobalWorkIT and discuss how it will build an EU-Korea network of ICT professionals to underpin trade between the two regions, secure industry sponsorship for future mobilities and enhance co-operation between the education partners and ICT companies.
\end{abstract}

The paper introduces the primary activities involved in GlobalWorkIT, which are:

(1) An integrated EU-Korea student mobility programme with industry experience. This includes: (i) industry experience with an innovation-oriented and internationally focused ICT multinational or small and medium enterprise (SME) company, or research institute (ii) accredited modules in specialist computer science topics (iii) Cultural and linguistic training in the Korean and English language and (vi) Cultural studies training. The student mobility target is four months' duration in any semester each year.

(2) An online module - 'The Global Classroom'. A unique feature of GlobalWorkIT is the semesterlong Global Classroom module, which is delivered online across time zones, countries and cultures and is unique and innovative. Delivered by the School of Computing at the Dublin Institute of Technology (DIT) in its Bachelor in Computer Science (International) programme, it aims to mimic the experience of workers in the international ICT industry. The student's international experiences are captured by using work practices in the global ICT industry (e.g. teleconferencing, time differences, project management in geographically distributed context, etc.,). The module is fully accredited and formally assessed and students of multiple nationalities take the module. It will be available to all students participating in the mobilities between the European Union (EU) and Korean participant institutions. This will extend the reach of the Global Classroom to allow for an 'internationalisation at home experience' for students who cannot travel abroad for personal, financial, health or other reasons.

(3) An internationalised curriculum in Computer Science. Over the course of the cooperation between the EU and Korean partners, a new internationalised curriculum leading to a joint double degree will be developed. Experiences captured, for example innovative curricula, new teaching methods, real world case studies, etc., will inform the development of this double degree.

(4) A faculty mobility programme. The faculty mobility programme will support the student mobility programme, the delivery of the Global Classroom module and the development of internationalised computer science curriculum.

Keywords: GlobalWorkIT, Higher Education Institutes, Global Classroom, Internationalisation, Computer Science, Curriculum, Student and Faculty mobility, ICT, EU, Korea 


\section{INTRODUCTION}

Within the context of European Union (EU) and Korean relations including the needs of the Information and Communications Technology (ICT) sector in both regions, the goal of GlobalWorkIT is to prepare European and Korean students for employment in the international ICT industry by enhancing mutual understanding of global ICT issues, languages and cultures. It connects three European and three Korean Higher Education Institutions located in world-leading ICT sectors (Ireland, Korea, Finland and Germany). Fig. 1 is a symbolic illustration of how the GlobalWorkIT facilitates this international connectivity.

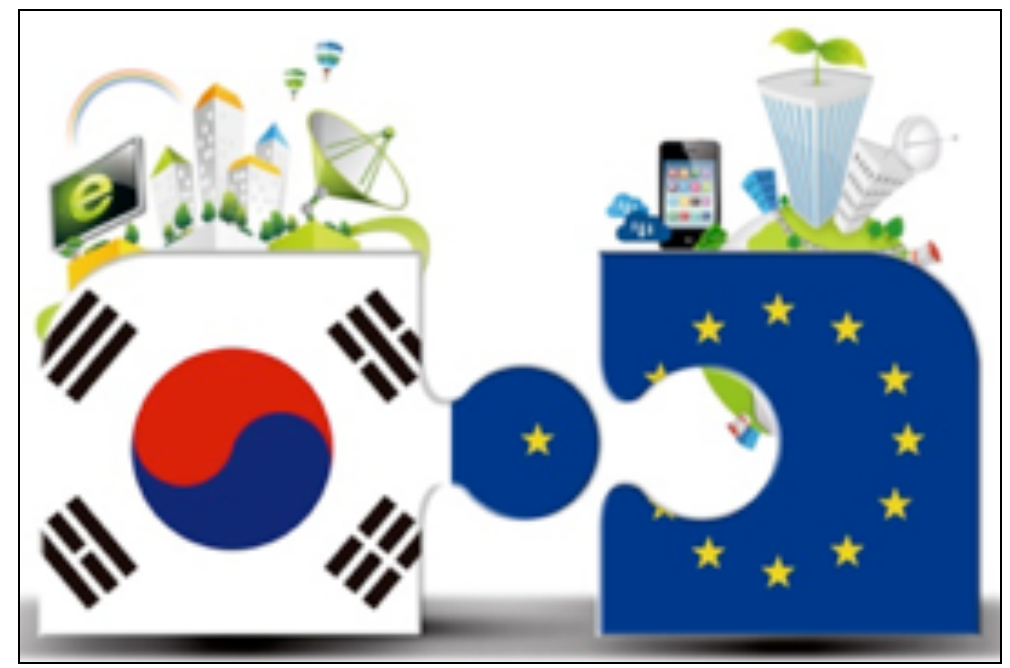

Fig. 1: GlobalWorkIT - Enhancing understanding between Korea and EU Higher Education Institutions

The targeted approach of connecting world leading ICT sectors in Ireland, Korea, Finland and Germany, and connecting the largest Schools of Computer Science in these regions, is an innovative approach which has critical mass on an international scale. GlobalWorkIT will encapsulate the experiences and lessons learned from previous international projects in the six partners into a 'capstone' internationalised computer science curriculum which has global relevance, providing a return on investment for current EU funding provided to support this project ${ }^{1}$ [1]. It therefore has the potential to impact the learning experiences of thousands of students over the next ten years. In the long term, GlobalWorkIT will lead to a sustainable relationship between the EU and Korean partner institutions and lead to a joint EU-Korea degree in Computer Science. A relationship between EU and Korean education and industry partners will be built and industry sponsorship for student mobilities beyond the lifetime of the project will be secured. Students will benefit by enhancing their employability through work and study experience in a very different culture [2]. They will develop their language skills and gain access to specialist computer science modules which might not be available in their home university.

Overall, a EU-Korea network of ICT professionals will be established which will underpin trade in the two regions for years to come. The online Global Classroom module is unique and innovative and it enables students to experience the complexities of working in an international ICT company, to share their own experiences and learn from the experiences of other students. The Global Classroom module also provides an 'internationalisation at home experience' for students that cannot travel abroad for personal or other reasons. The faculty mobility programme will enable staff to experience teaching in different cultures and compare didactic methods and student performance across the globe.

\footnotetext{
${ }^{1}$ EU-ICI Industrialised Countries Instrument (ICl) Education Cooperation Programme provides financial support for Joint Degree and Joint Mobility projects between the EU and Australia, New Zealand, Japan and the Republic of Korea in the field of higher education and vocational education and training.
} 


\section{OBJECTIVES OF GLOBALWORKIT}

GlobalWorkIT has the following primary objectives:

1. To implement an integrated, innovation-focused and industry-focused EU-Korea student mobility programme which includes computer science, cultural and linguistic training and industry experience (where applicable) for $36^{2} \mathrm{EU}$ and 63 Korean students.

2. To implement an online module ("the Global Classroom"), which students participating in the mobility programme and other students can take, providing an 'internationalisation at home' opportunity for students that cannot travel for personal, financial, health or other reasons.

3. To implement a faculty mobility programme which supports the other objectives of GlobalWorkIT for $18 \mathrm{EU}$ staff and 12 Korean Staff.

The student mobility facilitates the development of enhanced language skills, some of which are unlikely to be available in the student's home country (e.g. Korean, Finnish, Irish) and allows the student to appreciate the value of language learning. Their cultural awareness will be improved by being integrated into the daily life of their destination country and through building a network of international friends and colleagues [3]. They will gain experience of at least four distinctive cultures in the Global Classroom module. This module is a key driver for students to undertake industry preparation activities, e.g. prepare a CV and Linkedln profile aimed at securing employment in the international ICT sector, plan and conduct a professional interview in pursuit of work placement or a graduate position.

The semester-long Global Classroom module is a unique feature of this project, which is delivered online across time zones, countries and cultures. Delivered by the lead partner as part of its BSc. in Computer Science (International) in the School of Computing at Dublin Institute of Technology (DIT), it aims to mimic the experience of IT professionals solving real-world software problems in the international ICT industry.

The faculty mobility will enable the comparison of didactic approaches and student performance across the globe and assist with the development of real-world case studies for the internationalised computer science curriculum. Faculty will also develop of relationships with international companies through partner institutions. This will enable faculty to develop innovative curricula, apply new teaching methods and develop insights and connections into international companies through the partner institutions, thus offering and running international projects not only with the international partners, but also with their industry links.

\subsection{Added value of the project}

All partner institutions run Computer Science Bachelor Degree programmes and these, including their accredited international experience components, will be used as a basis for the student mobilities.

The lead EU partner, DIT, has developed a BSc. in Computer Science (International) programme that is designed specifically not just to meet the needs of the Irish ICT sector, but also other important skills that international companies require from their employees. Beyond a 'traditional computer science degree', an internationalized computer science curriculum includes a greater emphasis on the following:

1. Designing user interfaces in the context of the Global Software Market based on culturallyaware Human Computer Interface principles.

2. Managing software projects in an international environment which includes business, cultural, legal political and social considerations.

3. Issues associated with internationalisation and localisation of software for global use.

4. The implications of cultural diversity for the design of global software products using a range of localisation processes.

There are few 'real world' experiences, teaching materials and case studies available to support the delivery of this curriculum. A curriculum and industry engagement models review between EU and Korean partners will be undertaken. Capturing lessons learned will inform the internationalisation

\footnotetext{
${ }^{2}$ Number of EU student scholarship beneficiaries of the 2014 EU-ICI funding provided for the GlobalWorkIT Joint Mobility Project.
} 
agenda in the Computer Science discipline and therefore the outcomes of this project have wide applicability for the Computer Science discipline internationally.

\section{STUDENT MOBILITIES}

The student mobilities were decided to be aligned between partners to the normal Spring and Fall semesters over the duration of the project. These would be of a 4-month duration in which the students would select and study a number of modules with an aggregated total of the equivalent of 30 European Credit Transfer System (ECTS). The Global Classroom would be a mandatory module that all mobility students must take and worth 10 ECTS. Due to the cultural diversity of the EU and Korean partners, it was decided to allow each student select one cultural-oriented module (e.g. Korean culture and history, English for academic purposes) to allow them gain knowledge of their host country, which would not normally be available. This would also demonstrate the international educational focus of this project.

All partner institutions offer a 'pre-departure orientation' about the host-university, country, visa, and other essential information to participating students. Mobility students develop their Student Learning Agreement and agree it with their home institution as part of this orientation. In addition, host institutions also offer an 'on-arrival orientation', which includes information on academic studies, university, campus, facilities, region and other crucial information with a relevant faculty member at the beginning of their exchange. All mobility students are entitled to use all student services and facilities, which are provided to local students in the host institution. These include access to the campus libraries, use of computers, student societies, counselling services and student service centres. Each host institution will provide the following:

- An Academic Advisor for the Student Learning Agreement

- International Office for logistical issues (e.g. student card issuance, campus tour, university festivals, local events, insurance, health concerns, visa issues, alien registration, language tutoring/exchange etc.,

Each partner has agreed that all exchange students will stay at an International Dormitory on campus or at an equivalent approved student accommodation. Exchange students are also encouraged to participate in various international activities organized by the hosting university. Many students also get involved in activities such as social parties to present their nation and culture, student clubs and meetings, which included visiting sites with historical heritage and cultural attractions.

\subsection{Tuition and Academic Credits}

The GlobalWorkIT project facilitates an exchange programme in which all students studying abroad will pay tuition and fees at their home institution only and will incur no additional payments to the host institution (except for a small additional fee at the German partner which covers services that includes public transportation, student canteen, etc.,). Students will not pay additional fees for tuition, registration, examinations and the use of library and laboratory facilities at the host institution.

At the project commencement meeting in October 2014, credit mappings were agreed between the EU and Korean partners for the ECTS and the Korean Credit Transfer system. This equates to be 5 ECTS $=3$ Korean credits. It was also agreed that all students participating in this exchange project must take a minimum workload of an equivalent of 30 ECTS while on exchange at any of the 6 institutions. It was agreed that all institutions will make a list of modules available for students to select at least one month prior to the start of each semester.

\subsection{The Global Classroom}

The Global Classroom is an on-line module made available to all students participating in the mobility scholarship programme. It is an accredited module worth 10 ECTS on DIT's BSc in Computer Science (International) programme and delivered by the School of Computing in collaboration with faculty from the partner institutions over one semester. This module is mandatory, delivered over one semester and is formally assessed and all students who receive a mobility scholarship must select it. It extends to students that cannot participate in actual international mobility for personal, health or financial reasons by enabling an 'internationalization at home' experience. The module is the foundation of the GlobalWorkIT project and has been specifically designed to mimic the globalized worker experience in 
its delivery mechanisms. In essence, a single virtual classroom is created with students regardless of their location.

The Global Classroom delivers a suite of extra skills, which include:

- Working in a teamwork environment distributed across many international locations, taking into account practical issues such as time zones and technology challenges.

- Understanding the day to day issues involved in international travel, including the accommodation market, legal rights, health system, labour market, social welfare system and financial and banking systems in the host country.

- Implementing a regular on-line reporting mechanism in support of work and study in the international context.

To date, the Global Classroom has run each semester since the Spring semester 2015 after the commencement of this project. The weekly Global Classroom sessions are chaired by faculty mostly from DIT with additional faculty members from the other partner institutions. As members of the Global Classroom, students are assigned to multi-location teams and given the task of selecting a team leader who acts as coordinator for all events that take place. Individually, the students can access online lectures delivered by faculty members from each partner as well as meet with their faculty mentor on-line who advises them on their work progress. The on-line lectures include topics related to multiculturalism, team-based software development, international cooperative research, etc., The major assessment delivery for each team is a substantial software design and development project, which includes an on-line group presentation as well as associated documentation and an individual interview.

\section{FACULTY MOBILITIES}

All home institutions ensure that each participating staff is fully briefed on the objectives of the faculty mobility programme and agree a plan for faculty mobility with the host institution. All partners will provide assistance on logistical issues such as visas, travel, insurance. Since faculty mobilities are of one-week duration, staff will most likely stay in hotels close to the host institutions.

The faculty mobilities support not only project management related matters but also academic (teaching and engagement) activities between all the partners. This mobility is seen a key driver in providing international project management experience to the EU and Korean lead partners as well as international academic experience to all the partners.

Other activities conducted at each project meeting included:

- Public lectures to the host institution faculty members on the education system in the partner's home university

- Korean partners advising about summer school programmes that run for approximately 1 month during the summer and the possibility of EU partner faculty applying to deliver modules

- The delivery of the Global Classroom module

- Industry engagement and site visits to major companies such as Samsung Electronics, Hyundai Heavy Industries, etc.,

Fig. 2 shows the faculty mobility workflow for each project meeting and all actions provided by the hosting partner to facilitate the visiting faculty members. 


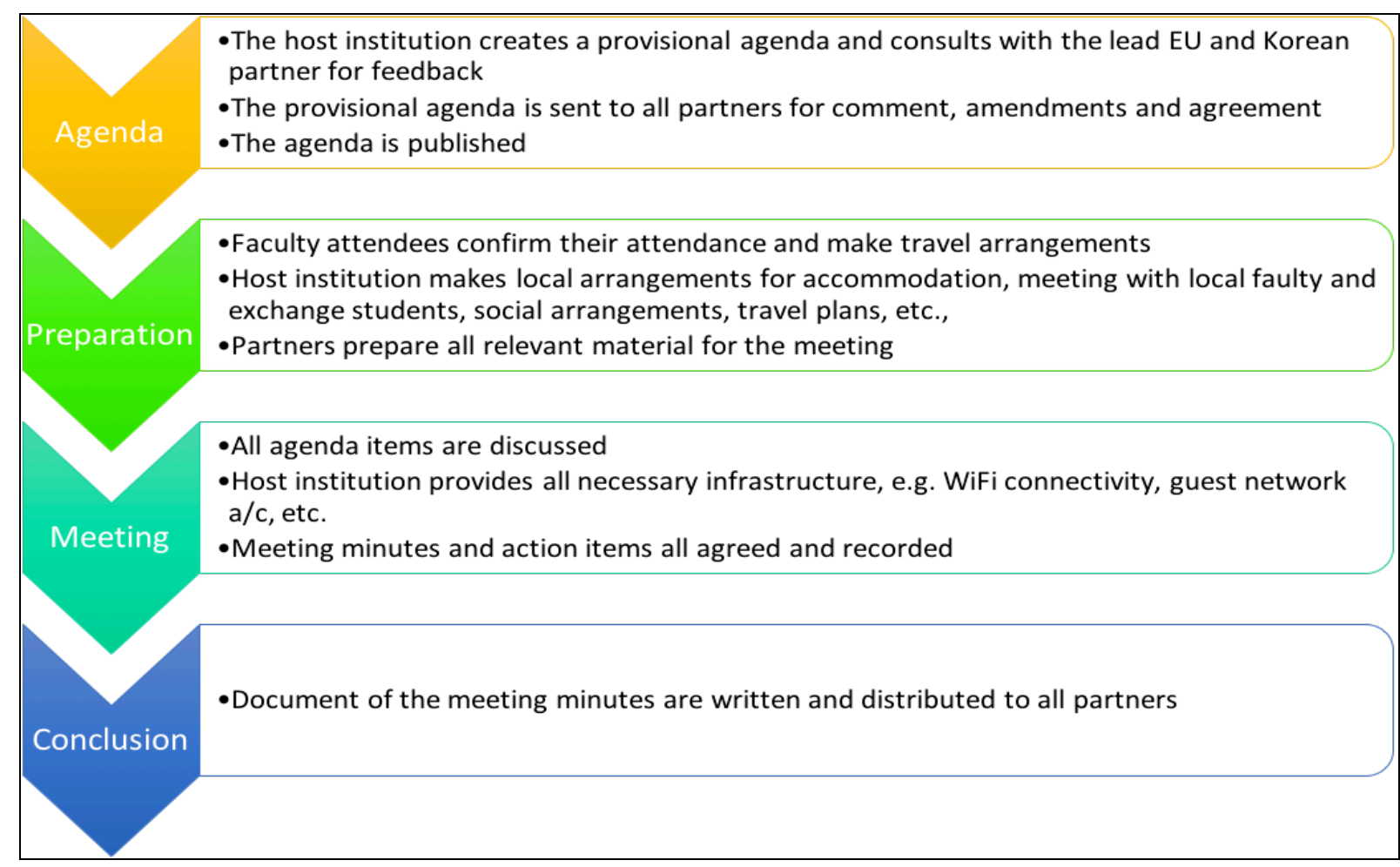

Fig. 2: Faculty mobility workflow for a collaborative project meeting

The faculty mobilities also allowed staff from each partner to meet with students from their institutions on exchange and discuss their progress. This allowed any issues raised to be immediately addressed and resolved where possible. It also allowed staff to observe teaching methods, attend lectures as guests, give guest presentations in specialized modules and meet with researchers.

\section{EVALUATION}

Continuous evaluation is part of the work plan for the GlobalWorkIT project and allows each partner to measure and adjust where necessary the agreed deliverables. Table 1 shows a sample of some evaluation targets achieved at the mid-point of the three-year project in March 2016.

Table 1: Evaluation targets and their status

\begin{tabular}{|c|c|c|}
\hline $\begin{array}{l}\text { Key Performance } \\
\text { Indicator }\end{array}$ & Target to meet & Current Status \\
\hline Student enrolment numbers & $\begin{array}{l}18 \text { (Exactly half of the } \\
\text { student mobilities used) }\end{array}$ & $\begin{array}{l}\text { All EU partners are actively recruiting } \\
\text { students who have expressed an interest } \\
\text { in participating on the exchange to Korea }\end{array}$ \\
\hline $\begin{array}{l}\text { Student completion of their } \\
\text { exchange }\end{array}$ & \begin{tabular}{llr}
$100 \%$ & \multicolumn{2}{c}{ completion } \\
including & acquiring & the \\
required & minimum 30 \\
ECTS & &
\end{tabular} & $\begin{array}{l}\text { All EU exchange students have } \\
\text { successfully completed their exchange at } \\
\text { one of the Korean partner institutions. }\end{array}$ \\
\hline Global Classroom delivery & $\begin{array}{l}100 \% \text { pass rate by all } \\
\text { students }\end{array}$ & $\begin{array}{l}\text { All EU and Korean exchange students } \\
\text { participating in this project must take the } \\
\text { Global Classroom module. To date, all }\end{array}$ \\
\hline
\end{tabular}




\begin{tabular}{|c|c|c|}
\hline & & students have successfully passed. \\
\hline $\begin{array}{l}\text { Distribution of student } \\
\text { mobilities to each Korean } \\
\text { partner institution }\end{array}$ & $\begin{array}{l}\text { Equal distribution among } \\
\text { all three Korean partners }\end{array}$ & $\begin{array}{l}\text { Each Korean institution can support } 4 \\
\text { student mobilities from each EU institution }\end{array}$ \\
\hline $\begin{array}{l}\text { External recognition and } \\
\text { dissemination of the } \\
\text { programme }\end{array}$ & $\begin{array}{l}\text { Teaching awards, } \\
\text { commendations, adoption } \\
\text { of practices in other } \\
\text { programmes, enquiries, } \\
\text { visits from staff at } \\
\text { institutions outside of the } \\
\text { consortium }\end{array}$ & $\begin{array}{l}\text { The project has been publicized internally } \\
\text { in all partner institutions among faculty } \\
\text { and students using email, notice boards, } \\
\text { information sessions, etc., DIT have also } \\
\text { contacted the Korean embassy in Ireland } \\
\text { as well as the Irish embassy in Korea and } \\
\text { updated the respective ambassadors } \\
\text { about this project. Both embassies have } \\
\text { given their full support. The Irish } \\
\text { ambassador in Seoul hosted a reception } \\
\text { in April } 2016 \text { for all project partners } \\
\text { attending the } 4^{\text {th }} \text { consortium meeting. } \\
\text { Representatives from the German and } \\
\text { Finnish embassies to Korea also attend. }\end{array}$ \\
\hline Faculty mobility & $\begin{array}{l}6 \text { (Half of all funded } \\
\text { faculty mobilities used) }\end{array}$ & $\begin{array}{l}\text { All EU partner faculty members have } \\
\text { attended all project consortium meetings } \\
\text { in Korea }\end{array}$ \\
\hline $\begin{array}{l}\text { Number and type of further } \\
\text { activities extending beyond } \\
\text { the GlobalWorkIT project }\end{array}$ & $\begin{array}{l}\text { Further projects, research } \\
\text { outputs, etc. }\end{array}$ & $\begin{array}{l}\text { At the } 3^{\text {rd }} \text { project consortium meeting } \\
\text { (mid-point of project), all partners began } \\
\text { discussions for sustainability between } \\
\text { each institution at the conclusion of the } \\
\text { project. Suggestions included joint } \\
\text { degrees, faculty exchanges for a } \\
\text { semester or year, applications for future } \\
\text { funding proposals, etc. }\end{array}$ \\
\hline
\end{tabular}

\section{CONCLUSION}

The GlobalWorkIT project is a three-year Joint Mobility project between three EU and three Korean educational institutions. Funding for the EU partners was provided by the EU under the EU-ICI funding mechanism and provides up to 36 student scholarship mobilities to a Korean partner and 12 faculty mobilities for consortium meetings hosted by the Korean partners. Since the commencement of the project in October 2014, it has facilitated an integrated, innovation-focused and industry-focussed student mobility programme, which includes computer science, cultural and linguistic training and industry experience (where applicable). The project has also facilitated the implementation and delivery of the Global Classroom, a unique on-line module that provides an 'internationalisation at home' opportunity for students that mimics a globalized worker's experience in a team environment in the design and development of a large-scale software solution. Finally, the project has supported faculty to travel to Korea and engage in teaching classes, giving seminars, as well as manage the project during collaborative project meetings at each Korean institution.

The fundamental essence of the GlobalWorkIT project is to prepare European and Korean students for employment in the ICT industry by enhancing understanding of global issues in the ICT sector and of language and cultural differences in the world. We believe this project has been very successful to date at broadening the minds of both students and faculty who have participated in this unique educational model. 


\section{ACKNOWLEDGEMENTS}

The authors wish to acknowledge the EU as the funding body to the three European partners under the Industrialised Countries Instrument (ICl) funding model for higher education and vocational training in cooperation with Australia, New Zealand, Japan and the Republic of Korea.

\section{REFERENCES}

[1] EU-ICI ECP Education Cooperation programme Australia, Japan, New Zealand and Republic of Korea, http://eacea.ec.europa.eu/bilateral_cooperation/eu_ici_ecp/index_en.php (correct as at Jan $5^{\text {th }}, 2017$ ).

[2] Kemal Guruz, "Higher Education and International Student Mobility in the Global Knowledge Economy," State of University of New York Press, Albany, 2011.

[3] R Brooks, J Waters, "Student Mobilities, Migration and the Internationalization of Higher Education," Palgrave Macmillan, 2011. 